\title{
A PROPOSTA DE CONCORDATA COM A SANTA SÉ E O DEBATE NA CÂMARA FEDERAL
}

\author{
ROSELI FISCHMANN $^{* *}$
}

\begin{abstract}
RESUMO: O acordo que a Santa Sé pretende do Estado brasileiro, ou seja, a concordata firmada pelo ministro das Relaçōes Exteriores, em nome do Poder Executivo, no Vaticano, tramita na Câmara dos Deputados no momento em que se finaliza este artigo, demonstrando, pelas repercussões e problemas, a gravidade da violação do princípio da laicidade do Estado, ferindo a Constituição. Aqui serão tratados aspectos do Estado laico assediado, bem como o envolvimento do campo acadêmico e iniciativas da sociedade em defesa da Constituição, buscando apresentar e analisar o tumultuado encaminhamento, sob pressão de regime de urgência, do texto na Câmara dos Deputados, enquanto se aponta as principais controvérsias desencadeadas.
\end{abstract}

Palavras-chave: Estado laico. Concordata. Santa Sé. Câmara dos Deputados. Ensino religioso.

\section{The Holy See concordat proposal and the Debate at THe Chamber of Representatives}

ABSTRACT: The agreement the Holy See proposes to Brazil, that is, the concordat signed at the Vatican by the Ministry of External Relations on behalf of the Federal Executive Authority, is submitted to the National Congress at the time this paper is written. Its repercussions and problems show how much, if passed, it violates the principle of a laic State, provided for by the Brazilian Constitution. This text discusses some aspects of the harassed laic State,

* Este artigo apresenta resultados combinados de dois projetos de pesquisa (CNPq e FAPESP).

** Doutora em Filosofia e História da Educação e professora nos Programas de Pós-Graduação em Educação da Universidade de São Paulo (USP) e Universidade Metodista de São Paulo (UMESP). E-mail: roseli.fischmann@uol.com.br 
the involvement of the academic field and civil society initiatives to defend the Constitution. It presents and analyzes the heated discussions on the concordat at the Chamber of Representatives and points out the mains controversies.

Key words: Laic State. Concordat. Holy See. Chamber of Representatives. Religious education.

\section{O Estado laico assediado}

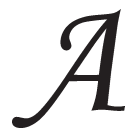

pressão da Santa Sé sobre o governo brasileiro para obtenção de um acordo jurídico que estabelecesse novos privilégios e consolidasse outros, vivenciados pela Igreja Católica no Brasil por décadas à margem da lei, provinha de antes da assinatura da proposta de concordata entre o Brasil e a Santa Sé, em 13 de novembro de 2008, ocorrida no Vaticano. Antes, houve dois anos de resistência, de diversas origens, empreendida por defensores da Constituição brasileira e do Estado laico, pois, se homologado aquele acordo, feriria o artigo 19 da Constituição brasileira, rompendo a tradição republicana de 120 anos de regime jurídico de relação entre o Estado e as religiōes de separação.

As primeiras evidências já tinham vindo à tona por ocasião do convite feito, a alguns pesquisadores, pela Secretaria de Educação Continuada, Alfabetização e Diversidade (SECAD), do MEC, para "uma discussão preliminar acerca do ensino religioso como área do conhecimento", que se realizaria em meados de novembro de 2006. Essa "discussão preliminar", que seria organizada como reuniāo preparatória de um seminário que ocorreria em dezembro do mesmo ano, foi por fim suspensa, em resposta aos protestos que gerou.

Mas o que se mostrou fonte de maiores indagaçôes e provocou mobilizações foi o artigo publicado no jornal Folha de S. Paulo (Fischmann, 2006), que se incumbiu de denunciar o processo que se fazia de forma silenciosa, longe dos olhos da cidadania:

Um senhor que se apresentou, então [em um congresso sobre liberdade religiosa], como advogado da CNBB e da Nunciatura Apostólica disse que estariam quase totalmente prontos os termos de uma concordata entre o Vaticano e o Brasil. É sabido, por exemplo, que esse tipo de acordo para definir cooperação entre o Vaticano e outros Estados foi assinado por Hitler e Mussolini. Afirmou ainda o advogado que a concordata seria 
"muito completa, com repercussões legais, políticas, administrativas, tributárias e financeiras", que a decisão do Papa de vir ao Brasil [em 2007] estaria ligada a isso.

Uma primeira fase desse processo de desvelamento se deu no período de seis meses, entre novembro de 2006 - quando, por intermédio do artigo acima mencionado, tornou-se público que estava em curso uma negociação, até então a portas fechadas, entre o governo federal e a Santa Sé sobre os termos de uma concordata -, e a visita do papa Bento XVI ao Brasil, em maio de 2007. Naquela fase, houve três tipos de processos interligados de reação, sendo dois de resistência e um de acomodação e busca de abafamento; esses processos continuaram a repercutir, sendo cada qual multiplicado internamente, e constituem o quadro atual, quando o texto do acordo tramita na Câmara dos Deputados, ainda antes de qualquer votação.

Um processo de resistência à possível violação da Constituição foi desencadeado por minorias religiosas e movimentos sociais diversos, com forte presença do movimento de mulheres e do movimento feminista. ${ }^{1}$ Esses grupos fizeram o alerta sobre o encaminhamento da proposta de aliança entre a Igreja Católica e o Estado brasileiro, usando a figura de acordo bilateral para tentar tornar aceitável o que já se apresentava como inconstitucional; os mesmos grupos buscaram informações, tanto de cunho histórico, para compreender o uso pela Igreja Católica da estratégia de concordatas na relação com os Estados, quanto de esclarecimento sobre as possíveis repercussóes legais de semelhante instrumento jurídico internacional.

Passou a chamar atenção, particularmente, que se tratava de estratégia semelhante à desencadeada há cerca de um século pelo Vaticano, ao relembrar que, pouco antes da Segunda Guerra Mundial, o cardeal Pacelli, depois papa Pio XII, dedicou-se a promover a elaboração e assinatura de concordatas como forma de marcar a presença do Vaticano no cenário internacional, aumentando seu poder político em diferentes países, como também em caráter mundial, pela multiplicidade de acordos bilaterais (Cornwell, 2002).

Esse primeiro momento foi alvo de estudos anteriores (Cunha, 2009; Fischmann, 2007a; Lorea, 2007), não sendo por isso objeto de análise aqui, mas vale lembrar brevemente que uma vertente derivada, no interior mesmo desse processo mais amplo, foi representada por 
debates sobre a eventual exacerbação de ameaças ao Estado laico pela proximidade da visita papal em 2007. Nesse contexto, dois temas chamaram a atenção: a tentativa de busca de estabelecimento do feriado de frei Galvão e o fato de o presidente Lula não beijar a mão do papa, quando de seu encontro em São Paulo, no início da visita papal ao Brasil.

Uma repercussão relevante e complementar, demonstrando que o fenômeno não era circunscrito a um determinado partido, mas que tomava por um lado o PT e, por outro, seu adversário, o PSDB, foi a mobilização, afinal vitoriosa, que se desencadeou contra a sanção, pelo governador de São Paulo, do Projeto de Lei "Deus na Escola" (Fischmann, 2007b). Esse lembrete com relação aos partidos políticos serve para indicar um primeiro aspecto complexo no tema, qual seja: a estratégia de pressão sobre os governantes, buscando atropelar a laicidade do Estado, tem sido feita de forma suprapartidária por parte dos partidários da união do Estado com a Igreja Católica, diferentemente do que estabelece a Constituição, que é a separação entre Estado e todas as religióes, indistintamente. Assim, em uma visão diacrônica, dois anos depois a proposta de acordo desenvolvida e assinada pelo governo do presidente Lula, do PT, encontrou em seus adversários do PSDB os mais fiéis aliados.

Uma segunda vertente de resistência foi representada por mobilização de parlamentares que, em contato com acadêmicos ligados ao tema e também com movimentos sociais, fizeram requerimentos solicitando ao Ministério das Relaçôes Exteriores informações e audiência pública para o tema específico do ensino religioso nas escolas públicas, no contexto da concordata que o Vaticano requeria ao governo brasileiro. Nesse primeiro momento, em 2007, vale mencionar os nomes de Ivan Valente (PSOL-SP), Fernando Gabeira (PV-RJ) e Raul Jungmann (PPS$\mathrm{PE}$ ) como sendo os que se posicionaram de forma inequívoca. Este é um segundo aspecto do tema, que se refere ao fato de que iniciativas regimentais, à disposição dos parlamentares, podem ser efetivas na defesa da Constituição ameaçada, em particular no que se refere às relações entre Estado e religióes.

Passando agora à vertente denegatória - e, correlacionada a ela, a de busca de alternativas de acomodação à pressão -, evidenciou-se tanto de setores da hierarquia religiosa católica, quanto de políticos seus 
aliados, em particular na fase de apresentação do acordo em forma de proposição ao Congresso Nacional.

\section{Iniciativas do campo acadêmico em defesa da Constituição}

Vale lembrar que a comunidade científica tem se feito presente no debate em defesa do Estado laico de diversas formas, de modo interdisciplinar, sendo a prontidão demonstrada no primeiro momento, acima mencionado, a expressão de reflexão coletiva e debate acumulado de décadas. Assim, a comunidade acadêmica pôde demonstrar seu posicionamento, com repercussão importante na imprensa e em blogs diversos que repercutiram as iniciativas. Cunha (2009) relembra temas que estavam em discussão no Supremo Tribunal Federal por essa época, envolvendo diretamente a participação de cientistas e a própria atividade científica em si, com relação à pesquisa com células-tronco embrionárias e à interrupção de gravidez em casos de anencefalia.

Embora o tema da relação entre ciência e religiôes não seja novo - ao contrário, a história traz exemplos de tensões e conflitos, particularmente em momentos de descobertas que contrariaram a autoridade religiosa -, a ameaça da perda da laicidade estatal, implantada e garantida pelo regime republicano, fez com que houvesse uma mobilização específica em torno do tema. Diversos periódicos publicaram e têm publicado números com a laicidade do Estado como tema, ${ }^{2}$ seminários foram realizados às vésperas da visita do papa Bento XVI em maio de 2007, em iniciativa interestadual, envolvendo diversas universidades, ocorridos no Rio Grande do Sul, Rio de Janeiro e São Paulo, incluindo participantes internacionais. ${ }^{3}$

Ainda dessa fase, a 59a Reunião Anual da SBPC, realizada em julho de 2007, em Belém (PA), teve atividades sobre o tema, algumas organizadas em colaboração com a ANPEd. ${ }^{4}$ Contudo, de especial repercussão foi a moção aprovada na Assembléia Geral da entidade. Apresentada com o dobro de assinaturas necessárias para ser incluída na pauta e contando com nomes da diretoria, do conselho e de secretários regionais como seus signatários, o texto da moção foi incisivo:

A sBPC apóia o presidente da República em seu compromisso de garantir o Estado laico e manifesta sua rejeição a toda tentativa de interferência de instituiçôes religiosas sobre o Estado brasileiro e de interferência de 
outro Estado sobre assuntos de soberania nacional. Repudia toda interferência exógena à comunidade científica que possa sinalizar ruptura com os valores universais e a independência da ciência. Alerta para os aspectos de inconstitucionalidade da forma como vem se processando o ensino religioso em escolas públicas, ferindo diversos direitos de crianças e adolescentes. (Jornal da Ciência, 2007)

O ano de 2008 foi de consolidação de debates, com seminários ocorrendo em diferentes estados, por iniciativa tanto de entidades acadêmicas em atividades ligadas a grupos de pesquisa, na USP e na UFRJ, entre outras, como também por iniciativa de organizações não-governamentais, com missão de pesquisa e reflexão, não apenas para o ativismo, como Católicas pelo Direito de Decidir, Comissão de Cidadania e Reprodução (CCR, ligada ao CEBRAP), entre outras entidades. A Comissão de Cidadania e Reprodução, por intermédio do Programa de Saúde Reprodutiva (PROSARE), abriu em 2007 um edital de concurso de projetos, com financiamento da Fundação MacArthur, de Chicago, no qual uma das linhas era especificamente voltada para o tema do ensino religioso em escolas públicas (EREP), cada projeto com um ano de duração e apresentado de forma integrada em seminário realizado em dezembro de 2008, afora seminários que foram realizados por iniciativa de diferentes instituiçôes apoiadas por aquele programa, como Ação Educativa e projeto DPE-FEUSP, havendo tanto iniciativas independentes como em colaboração entre diferentes instituições.

As iniciativas acadêmicas resultaram também em colaborações com a imprensa. Assim, além da intensa exposição da opinião pública, em 2007, ao tema, por rádio, TV, jornais de circulação nacional, em 2008 foram apresentados resultados desses projetos também em publicações na grande imprensa, como o número da revista Época que dedicou a matéria de capa ao EREP (Aranha \& Mendonça, 2008). $\mathrm{Na}$ mesma linha, a CBN, em particular em entrevistas matinais no Jornal da $C B N$, com o jornalista Heródoto Barbeiro, dedicou vários programas tanto ao tema do EREP, quanto especificamente ao tema da laicidade do Estado.

Um exemplo de iniciativa acadêmica relevante, por essa época, é a criação do Observatório da Laicidade do Estado (OLE), junto ao Núcleo de Estudos de Políticas Públicas em Direitos Humanos, da UFRJ. Iniciado em 2007, tem reunido pesquisadores de diferentes áreas e instituições, em esforço de cooperação coletiva na coleta 
e análise de documentos, além de haver promovido seminários e mesas redondas sobre a concordata.

\section{Outras iniciativas e questões do campo social}

Vale notar que em maio de 2008, foi fundada a Associação Brasileira de Ateus e Agnósticos (ATEA), que adota como um de seus princípios estatutários "a separação entre o Estado Brasileiro e instituições religiosas, seja em esfera Federal, Estadual ou Municipal, no exercício da administração direta ou indireta" (ATEA, 2008). Lideranças ligadas à fundação da Associação vinham buscando formas de inserção, no cenário nacional, para o combate aos diversos tipos de discriminação de que ateus e agnósticos são frequentemente alvo no Brasil, notadamente por meio de campanhas.

Desse tipo de iniciativa, realizada em conjunto com diversos setores da sociedade, incluindo representantes religiosos, juristas, entre outros grupos, ganhou particular reconhecimento a campanha "Brasil para Todos", em prol da retirada de símbolos sagrados de espaços públicos, notadamente com algumas vitórias conseguidas após inúmeras açōes apresentadas junto a diferentes órgãos, em diferentes estados. ${ }^{5}$ Essa campanha conta com participantes de diferentes orientaçôes filosóficas, espirituais e religiosas, não apenas ateus, uma vez que tem origem plural a reivindicação de que o espaço público, vinculado ao Estado laico, seja liberado de quaisquer símbolos religiosos.

Assim, no contexto da atuação dos fundadores e ativistas da ATEA, parece ser possível dizer que a atuação do grupo indica que a própria articulação em torno da defesa da Constituição contra o acordo buscado pelo Vaticano com o Brasil ${ }^{6}$ auxiliou para que se fizesse essa definição de identidade institucional, ampliando a presença desse grupo nos debates em torno da laicidade. Cabe, também, supor que essa melhor e mais específica definição de identidade institucional resultará em mais constante e articulada presença de ateus e atéias no debate de temas ligados à presença religiosa na esfera pública e à polêmica questão do ensino religioso em escolas públicas. Esse grupo social tem particular significado por representar a impossibilidade absoluta de qualquer tipo de aliança do Estado com o campo religioso, se o Estado de fato pretender ser democrático, de Direito, e tratar todos os cidadãos e cidadãs como livres e iguais em dignidade e direitos. 
Ainda no ano de 2008, houve uma atividade que jogou a temática do Estado laico literalmente em praça pública, quando a Associação da Parada do Orgulho GLBT decidiu que o tema de sua XII Parada, em São Paulo, em 2008, fosse "Homofobia mata - por um Estado laico de fato". Pinheiro (2008) indica a pertinência da escolha do tema, suscitado em grande medida pelos debates havidos em torno da ameaça de assinatura de um acordo entre o Brasil e a Santa Sé, indicando ainda aquela autora implicaçóes jurídicas, não atinentes apenas ao público específico daquela Parada:

A intransigente defesa, portanto, do regime de separação Estado-Igreja (lema da Parada GLBT 2008) traz como consequência inevitável a adoção de um posicionamento que rejeita qualquer grau de permeabilidade estatal ao pensamento religioso que resulte na adoção de políticas públicas que consagrem ou tornem impositiva uma específica verdade religiosa, em detrimento de todas as demais existentes no corpo social. Este repúdio a qualquer ato estatal caracterizador de verdadeira "escolha religiosa" tanto mais se acentua quando o resultado de tal eleição for a implementação, pelo Estado, de práticas ou condutas omissivas que, por sua natureza sectária e discriminatória, culminam por violar, frontalmente, normas e valores que são centrais ao estatuto fundamental das liberdades públicas, além de fundantes do próprio ordenamento jurídico-constitucional, como o são os valores da liberdade e da igual dignidade de todos.

Assim, o tema das implicações para relações homoafetivas, em particular quanto a arranjos familiares, e o tema dos direitos sexuais e reprodutivos, com suas repercussões para temas de saúde pública, como em particular no que se refere aos direitos das mulheres (Carneiro, 2008) e à descriminalização do aborto, ${ }^{7}$ compõem aspectos dos mais sensíveis a demonstrar a relevância da laicidade do Estado, no campo social e dos direitos humanos. Mas o tema do ensino religioso em escolas públicas, por se referir a crianças e adolescentes, e pela história acumulada no campo da educação (Cunha, 2009), tem sido a pedra de toque que suscita indignação coletiva quanto aos limites da ingerência das religiões sobre a formação de consciências tenras, por sobre, até, da vontade e determinação das próprias famílias, contra o caráter laico da proteção que o Estado brasileiro prevê oferecer à cidadania e ferindo o caráter facultativo previsto pela Constituição. É o tema que mais uma vez retorna como polêmica central, no encaminhamento no Congresso Nacional da concordata assinada em novembro de 2008. 
Ainda, no âmbito das novas formas de comunicação, um abaixoassinado contrário à concordata foi desenvolvido a partir da internet (Cunha, 2009), desencadeando a criação de um blog, que tem servido de depositário de reproduções de notícias, indicação de páginas na internet, artigos, entrevistas originalmente veiculadas no rádio e TV, documentos relativos à tramitação na Câmara, entre outros subsídios que, embora estruturalmente simples como todo blog, ou exatamente por isso, têm auxiliado como referência a quem se interesse pelo tema.

\section{A concordata na Câmara Federal}

$\mathrm{O}$ (des) caminho ${ }^{8}$ buscado para tentar encobrir a inconstitucionalidade da iniciativa, ou seja, o de valer-se de um acordo internacional, por um lado facilitou que a proposta se efetivasse preliminarmente, por ser, segundo a Constituição brasileira, competência privativa do presidente da República "manter relações com Estados estrangeiros e acreditar seus representantes diplomáticos" (art. 84, VII), bem como "celebrar tratados, convenções e atos internacionais, sujeitos a referendo do Congresso Nacional" (art. 84, VIII). Ou seja - e aqui entra o "por outro lado" -, a defesa da cidadania pode e deve ser feita pelo Congresso Nacional, no sentido de evitar que qualquer acordo inconstitucional seja efetivado entre o Brasil e qualquer outro Estado, mesmo sob alegação de "boa intenção", por parte do presidente da República e/ou de eventual Estado interessado em algo que não seja apropriado à ordem jurídica nacional.

Dessa forma, o texto assinado no Vaticano foi apresentado ao Congresso Nacional, transformando-se assim em proposição; iniciava, então, tramitação pela Câmara Federal em 13 de março de 2009, recebendo a referência MSC 134/2009. Contudo, a Mensagem do Executivo que apresenta o texto do acordo de 13 de novembro de 2009 foi assinada pelo embaixador Samuel Pinheiro Guimarães, secretário geral do Ministério das Relações Exteriores (MRE), em 12 de dezembro de 2008, ou seja, três meses antes da chegada do documento à Casa legislativa. Essa defasagem indica um lapso entre o texto de encaminhamento ao Legislativo, de responsabilidade do MRE, apenas um mês após a assinatura do texto do acordo, e seu efetivo envio, pelo Executivo. Teria sido essa delonga uma tentativa de deixar fenecer as manifestaçóes contrárias deflagradas imediatamente após a assinatura do acordo por parte da sociedade civil, como indicado por Cunha (2009)? 
Mais importante que a questão da data, todavia, são algumas informaçôes que, apenas ao ser apresentada ao Congresso Nacional, a Mensagem oferece à cidadania. De particular relevo para o debate é o fato de esse documento mencionar que houve um processo de elaboração que se prolongou por dois anos, com troca de textos prévios em negociaçôes entre o Executivo federal e a diplomacia da Santa Sé. No que se refere ao governo federal, então, esse processo de análise de propostas de textos de acordo envolveu dez ministérios (incluindo, por exemplo, o MEC, o Ministério da Saúde, a Casa Civil e o próprio MRE, que se identifica como coordenador do processo).

Surpreende que, em tramitação tão longa, por tantas áreas, por dois anos, jamais viesse a público o texto em negociação ou seu conteúdo, ficando entre poucos funcionários, submetidos à autoridade de seus superiores, nos ministérios envolvidos. Parece, pois, que a ausculta da sociedade civil jamais tenha sido considerada como sendo de relevo em processo tão grave, uma vez que nem foi mencionada na Mensagem de encaminhamento. No caso, por exemplo, do artigo 11 do texto firmado, que se refere ao ensino religioso em escolas públicas, tão longa é a tradição de debate no campo da educação, que é incompreensível que tenha sido desdenhada semelhante experiência e acúmulo reflexivo, tanto que chegaram a uma versão flagrantemente inconstitucional.

É evidente que o desprezo pela cidadania já se fez como sintoma de tendência de uma orientação política que não apenas se abre à aceitação de acolher estruturas religiosas no Estado, como vê de bom grado a possibilidade de nelas se apoiar; por isso, pede adesão e não análise, não se preocupando com a argumentação plural, própria da democracia, assim como descura da própria ordem jurídica vigente.

Assim, apesar de haver circulado por dez ministérios (sempre em nível de gabinete de ministros), durante dois anos, em diferentes versões de textos, o acordo foi encaminhado ao Congresso Nacional para que ali sua tramitação fosse a mais sumária possível: originalmente, foi determinado que seguisse para a Comissão de Relações Exteriores e Defesa Nacional (CREDN) e, então, para a Comissão de Constituição e Justiça, de praxe a última comissão por onde devem passar todas as proposições. Mas apenas essas duas comissões, nenhuma outra mais.

Após chegar à CREDN, o ministro das Relações Exteriores manifestou-se, pedindo urgência, e procurou propor que os acordos 
internacionais (entre os quais, o objeto da MSC 134/2009) fossem examinados em caráter terminativo naquela Comissão, sem seguir para o Plenário. Encontrou-se, ainda, pessoalmente com o presidente da CREDN, deputado Severiano Alves (PDT/BA), nesse sentido, para pedir que fosse a proposição examinada o mais rapidamente possível.

No encaminhamento ao Congresso Nacional houve ainda outras medidas de pressão, em particular por setores da Conferência Nacional dos Bispos do Brasil (CNBB), anulando assim qualquer argumento quanto ao caráter "internacional" do documento. Nessa pressão, o próprio presidente da CNBB compareceu em pessoa ao Congresso Nacional pelo menos duas vezes, conforme noticiado pelo sítio da Câmara Federal. Na primeira, foi ao presidente da CREDN, em um encontro que, conforme noticiado pela Agência Câmara, trazia a impressão de que nada havia a discutir. A essa altura, já fora indicado o relator, que igualmente se encontrou com a CNBB. Na segunda visita ao Congresso Nacional, o presidente da CNBB dirigiu-se diretamente ao presidente da Câmara, deputado Michel Temer (PMDB/SP), para pedir que o projeto seguisse tramitação em regime de urgência. De fato, essa segunda visita anunciava que a tramitação não estava se dando de forma tão tranquila e tão rápida quanto o esperado pela CNBB e pela Santa Sé.

Essa busca de celeridade explicava-se por algumas iniciativas de deputados que, ciosos de sua missão constitucional frente à peculiar proposta de acordo, escapavam ao previsível. Como gesto relevante, buscando propor debate mais amplo, o deputado Ivan Valente (PSOLSP) entrou com requerimento solicitando ao presidente da Mesa um mínimo de isonomia entre o Executivo e o Legislativo. Lembrava o deputado que, se no Executivo dez ministérios haviam analisado o texto, por que no Legislativo apenas duas comissões o fariam? Requereu assim que fosse a proposição analisada na Comissão de Educação e Cultura (CEC) e na Comissão de Trabalho, Administração e Serviço Público (CTASP). Justificava o pedido de encaminhamento à CEC com base no artigo 11 do acordo, que se refere ao ensino religioso em escolas públicas; e à CTASP, com base no artigo 16, que estabelece como sendo voluntário todo serviço prestado às instituições católicas, também negando vínculo empregatício a sacerdotes, religiosos e religiosas que trabalham para a Igreja Católica. O presidente da Mesa, deputado Michel Temer, despachou favoravelmente, com o que se ampliava 
o escopo do debate sobre a proposição no interior da Câmara, tornando menos simples a celeridade pretendida pela instituição interessada.

Simultaneamente, foram protocolados requerimentos de audiência pública por alguns deputados, trazendo diferentes propostas, porém todos voltados para a possibilidade de ouvir diferentes pontos de vista. $\mathrm{O}$ primeiro requerimento foi apresentado pelo vice-presidente da CREDN, deputado Damião Feliciano ( $\mathrm{PDT} / \mathrm{PB}$ ), sem especificação de nomes que poderiam ser convidados. Contudo, frente a outro requerimento, apresentado pelo deputado Dr. Rosinha (PT/PR), já com sugestão de nomes para aquela audiência pública solicitada, notadamente de apoiadores da laicidade do Estado, o primeiro requerimento foi retirado de pauta, a pedido do deputado autor do pedido. A seguir, mais três requerimentos foram apresentados, cada qual com pedido de audiência pública e indicando ou nomes individuais, ou indicação de entidades para enviar representantes; foram autores dos requerimentos os deputados Dr. Rosinha (PT/PR), Takayama, em conjunto com Jefferson Campos (PTB/SP), e George Hilton (PP/MG). Para compreender a forte polêmica que se instalou, então, nas sessões da CREDN, conforme registro em áudio da Câmara, é preciso mencionar um dos processos que ocorria nos bastidores, em paralelo, enquanto se protocolavam os requerimentos.

Sistematicamente, os pronunciamentos da CNBB denunciavam processo de tentativa de cooptação de outros grupos religiosos, conclamando a que "fizessem acordos iguais". Contudo, é amplamente sabido que a única religião ou, mais apropriadamente, denominação cristã que conta com personalidade jurídica de direito internacional (ainda que anômala, segundo Rezek, 2008), é a Igreja Católica, apresentando-se como Santa Sé e tendo a cidade do Vaticano como sede. Ou seja, se fosse constitucional um acordo internacional com a Santa Sé, estaria definitivamente instalada a quebra de isonomia entre as religiōes no Brasil, porque nenhuma outra poderia receber igual privilégio.

Contudo, a tentativa de oferecer às demais religiões alguma "compensação" levou à redação de uma minuta de Projeto de Lei (PL), apresentado extraoficialmente apenas nos bastidores, como "Lei Geral das Religiões" ou "Tratado Geral das Religiōes", como se referiram alguns deputados a esse esboço, quando sobre ele indagados em conversas informais. Seria apresentado como "Substitutivo do Relator", junto à proposição do PL 1553/2007, de autoria do deputado Dr. Talmir (PV/ 
SP). Esse PL, ao ser apresentado originalmente, tinha como ementa o texto: "regulamenta o Inciso vi do artigo $5^{\circ}$ da Constituição Federal, assegurando o livre exercício dos cultos religiosos, garantindo proteção aos locais de culto e suas liturgias e a inviolabilidade da liberdade de consciência”. Com razão, o relator, deputado George Hilton (PP-MG), considerou inconstitucional a proposição, uma vez que não é passível de ser regulamentado o que, sendo considerado cláusula pétrea da Constituiçãa Federal, é autoaplicável, no que se enquadra o direito à liberdade de consciência, de crença e de culto. Contudo, a existência desse PL passou a funcionar como apoio para uma proposta que não apenas não resolvia a questão da concordata pretendida, como a agravava.

O ponto central aí é que se evidenciava, de forma definitiva, que o artigo 19 da Constituição estava sendo claramente violado, porque, na tentativa de atender o inciso III, sobre a igualdade entre os cidadãos, ou o "princípio da isonomia", como se tornou fala corrente entre os deputados, feria de forma insanável o inciso I, que define o regime jurídico das relações entre o Estado brasileiro e as religiōes, como sendo o de separação. O que se propunha alterava esse regime jurídico e criava situações insolúveis, do ponto de vista tanto da laicidade do Estado, quanto da invocada isonomia. A bancada evangélica, como tem se denominado, era o alvo preferencial dessa proposta, que deputados chegaram a chamar em plenário de "acordão", ${ }^{9}$ o qual sugeria saída legislativa que supostamente contemplaria os mais diversos cultos. Evidentemente, a proposta surgia como reação a conflito inexistente entre grupos religiosos até a apresentação da concordata.

Ou seja, um foco de polêmicas dizia respeito à realização de audiências públicas, pelo receio que os partidários do acordo demonstravam quanto a abrir o debate. Outro foco de controvérsia residia na eventual possibilidade de equiparar, para outras religiões, os mesmos privilégios reivindicados pela Igreja Católica no acordo, e que não poderiam ser encarados como direitos, pois não encontram abrigo no texto constitucional, motivo pelo qual não convenceram, até aqui, os deputados evangélicos particularmente visados pelo processo de persuasão e cooptação. A resistência dos deputados evangélicos, adicionalmente, também se refere à consciência de que nada se equipararia, para as demais denominações e religiões, a um acordo internacional, se fosse aprovada a concordata, tornando irremediável a quebra de isonomia jurídica entre 
os diferentes cultos, que então ocorreria. A mera perspectiva dessa situação é, em si, fonte de tensão, controvérsia e indignação.

$\mathrm{Na}$ tramitação, foram quase dois meses de impasse quanto a realizar ou não uma audiência pública, em meio ao que o relator, deputado Bonifácio Andrada (PSDB-MG), apresentou parecer favorável à aprovação da proposição, sem esperar pela possibilidade de um debate advindo de uma possível audiência. Finalmente, uma solução de compromisso foi atingida pelos deputados da Comissão de Relaçóes Exteriores e Defesa Nacional, envolvendo também as lideranças partidárias, o qual foi parcialmente cumprido e parcialmente rompido. $\mathrm{O}$ acordo entre os deputados visou à retirada do requerimento para que a tramitação passasse para o regime de urgência, tendo como condição que os autores dos requerimentos relativos às audiências públicas - que indicavam nomes de representantes de diferentes religiões, ou mesmo nomes considerados, por alguns, como ligados a temas controversos aceitassem que a audiência fosse tratada como "painel" e que fossem convidados apenas um representante do Itamaraty e uma pesquisadora, ${ }^{10} \mathrm{a}$ autora deste texto, cujo nome foi aceito por todos, para tratar de aspectos conceituais envolvidos na concordata e sua problematização, subsidiando a CREDN.

A possibilidade de realizar finalmente uma audiência sobre o tema resultou em articulações da sociedade civil com pesquisadores e em diálogos de pesquisadores com deputados, além de atenção da imprensa, que até então estava entre hesitante e silente. Com a mobilização de diversos defensores da laicidade a Brasília para acompanhar a audiência pública, três deputados de diferentes partidos dirigiram-se ao presidente da Câmara, deputado Michel Temer (PMDB-SP). O deputado Ivan Valente (PSOL-SP) valeu-se das prerrogativas de líder de partido, apoiado pelo deputado Dr. Rosinha (PT-PR), responsável pela indicação do nome da pesquisadora convidada a falar na audiência, e pelo deputado André Zacharow (PMDB-PR), como correligionário do presidente da Casa, para conseguirem que o presidente Temer recebesse o grupo da sociedade civil, propiciando a pesquisadores e membros de ONGs e movimentos sociais manifestarem pedido para que a Câmara não adotasse regime de urgência em tramitação de projeto tão polêmico.

O grupo alertou quanto ao fato de que o texto do acordo violava o artigo 19 da Constituição, alterando o regime jurídico da relação entre o 
Estado brasileiro e as religióes, saindo do regime de separação para o de união. O presidente da Câmara sugeriu aos visitantes que procurassem os líderes, porque, segundo ele, sofria muitas pressôes para colocar logo em votação a proposição e que, no dia seguinte, votariam o pedido de urgência, o que, pouco antes, havia sido acertado em reunião dos líderes dos partidos. Contudo, cerca de uma hora depois desse encontro do grupo em prol da laicidade do Estado com o presidente da Casa, entrou na pauta de votação o pedido de urgência, rompendo o acordo, uma vez que não esperaram a audiência que haveria no dia seguinte. Foram 301 votos a favor da urgência e 49 contrários.

Suspensa em um primeiro momento, em razão de luto na Casa, e sendo remarcada para a semana seguinte, finalmente ocorreu, com a presença de um representante do Itamaraty e a pesquisadora convidada. A sessão lotou o plenário, tanto com a presença dos deputados da CREDN e assessores, quanto do público diverso, por quase quatro horas. Os deputados decidiram que era relevante continuar a sessão na semana seguinte, porque apresentaram diversas perguntas e esperavam poder obter esclarecimentos e mais informaçôes. Essa segunda sessão ocorreu regularmente, mantendo-se a mesma pesquisadora, sendo, contudo, outra a representante do Ministério das Relaçôes Exteriores (Agência Câmara, 2009a; 2009b).

A tramitação, a partir daí, recebeu novos aportes polêmicos, denunciando as diversas controvérsias presentes na proposta de acordo. Cinco deputados apresentaram votos em separado, contrários ao Parecer do Relator, a saber (pela ordem de apresentação): André Zacharow, pastor Pedro Ribeiro, bispo Gê Tenuta, Ivan Valente e Takyama. A votação do regime de urgência, contra a necessidade de debate e análise serena de processo tão controverso, não conseguiu calar as vozes discordantes.

\section{Perspectivas que se desenham no horizonte}

Entre as perspectivas que podem ser vislumbradas no momento em que a Câmara está em recesso, há controvérsias e uma tendência de reivindicação no campo social.

Tema já anunciado em seu voto em separado, o deputado André Zacharow apresentou, no início do recesso, requerimento solicitando 
esclarecimentos ao Ministério das Relações Exteriores, com relação ao acordo entre o Brasil e a Santa Sé sobre assistência religiosa às Forças Armadas, de 1989, assinado no final da presidência de José Sarney. O deputado, após fazer levantamento junto à Consultoria Legislativa da Câmara, apurou que o referido acordo nunca passou pelo Congresso Nacional, como exige a Constituição de 1988, motivo pelo qual não pode ser considerado como estando em vigor; ainda assim, desde que foi assinado, o acordo de 1989 tem sido aplicado, com dispêndios financeiros do Estado para sua efetivação; com isso, é possível instaurar ação popular ou ação civil pública, pois são mais de vinte anos de aplicação de verbas públicas em organismos irregulares, do ponto de vista da ordem jurídica. A relevância dessa apuração é que o artigo 20, do texto da concordata atualmente em discussão na Câmara, traz redação que, se aprovado o acordo, permitiria a convalidação daquele de 1989, sem qualquer debate. Assim, a adequada resposta ao que o deputado Zacharow solicita em seu requerimento condiciona a votação da proposição MSC 134/2009.

$\mathrm{O}$ artigo 11 do texto da concordata, que trata do ensino religioso em escolas públicas, suscitou grande indignação nos setores os mais diversos, tanto por obrigar o ensino religioso católico em todas as escolas públicas, apresentando-se como imposição às instituições públicas de ensino, o que é inaceitável, quanto por conter uma menção a "outras religiōes", levando à polêmica relativa à legitimidade da Igreja Católica para se manifestar em nome de outras religióes. Preocupado com a reação de setores tão diversos contrários ao acordo como um todo e a esse artigo em particular, o deputado pastor Pedro Ribeiro obteve no MEC e leu, em plenário, o Parecer n. 135/2009. Este parecer atende solicitação da assessoria parlamentar do gabinete do ministro e declara que a redação adotada nesse texto da proposição MSC 134/2009, firmada no Vaticano em 2008, é inconstitucional. São apresentados, para instruir o parecer, nota técnica e outros documentos oferecidos no decorrer da negociação com a Santa Sé; chama atenção o Aviso n. 1161/ 2008, do gabinete do ministro, de 16 de setembro de 2008, no qual é reproduzido o dispositivo constitucional referente ao EREP, para comparação com o que estava sendo solicitado pela Santa Sé, finalizando com a recomendação: "(...) sugerimos que o artigo 11 do Acordo em comento tenha a mesma redação do artigo $210 \$ 1^{\circ}$ da Constituição Federal, conforme transcrito acima”. 
O Parecer n. 135/2009, da Diretoria de Concepções e Orientações Curriculares para a Educação Básica, encaminha, "para as providências cabíveis", manifestação da Coordenadora Geral do Ensino Fundamental, que é taxativa: "Esta Coordenação manifesta-se desfavoravelmente à aprovação do artigo 11 do Estatuto Jurídico da Igreja Católica no Brasil”.

Sendo o documento datado de 2 de junho de 2009, apresentase como controvérsia de particular impacto, uma vez que, por estar em jogo um acordo internacional, a rejeição parcial do texto faz com que se necessite retomar o processo, uma vez que as duas partes precisam voltar a negociar os termos que aceitarão, ainda que em relação a um único artigo. Com essa polêmica, e pelo que representa para religiōes e famílias, o texto do artigo 11 do acordo, sobre ensino religioso nas escolas públicas, tornou-se um dos pontos de maior controvérsia relativa a essa proposição. No campo acadêmico não é diferente, tendo em conta a tradição de debate sobre o tema em faculdades, centros e nas entidades associativas de educadores, desde a década de 1950, que se manifestaram a partir de forte movimentação na Constituinte e na elaboração da LDB.

Fadado ao impasse, enquanto seus apoiadores evidenciam, por exemplo, na votação do regime de urgência, disposição para impor seu ponto de vista pela pressão e pelo constrangimento, a saída encontrada pelos defensores da laicidade e da Constituição é simples e é o que se apresenta como mais adequado para garantir a paz social. Presente em movimentos sociais, em discursos de deputados no Plenário (Câmara, 2009) e no meio acadêmico, é bem representada pela moção aprovada por unanimidade na Assembléia Geral da SBPC, em Manaus, em julho de 2009, servindo de conclusão para estas breves reflexōes:

A SBPC apela ao MRE para que solicite a retirada imediata da MSC 134/ 2009, ora em tramitação no Congresso Nacional, por encaminhar acordo cujo teor fere o Art. 19 da Constituição Federal, ao alterar o regime jurídico da relação entre o Estado brasileiro e as religiōes, ferindo o princípio da laicidade do Estado brasileiro e demais princípios conexos, como a liberdade de consciência, de crença e de culto.

Recebido e aprovado em agosto de 2009. 


\section{Notas}

1. A esse respeito, ver Oliveira (2006); Carneiro (2006); Comissão de Cidadania e Reprodução (2007).

2. Por exemplo, Nossa América - Revista do Memorial da América Latina, n. 26, 2007; Ciencia e Cultura, com participação do tema na edição especial Artigos \& Ensaios (Velho, 2008); diversos números do Jornal da Ciência, da SBPC, assim como do Observatório da Imprensa.

3. Afora nomes de destaque da luta em prol da laicidade no Brasil, compareceram a esses seminários, entre outros: Roberto Blancarte Pimentel, do Colégio de México; Micheline Millot, da Universidade de Quebec, em Montreal; Marco Antonio Huaco Palomino, da Universidade Nacional Maior de São Marcos, do Peru. Alguns dos participantes reuniramse na publicação organizada por Lorea (2008).

4. A parceria com a ANPEd promoveu: (a) o Simpósio Ensino público, religiāo e Estado laico, com a participação, como simposistas, dos professores Carlos Roberto Jamil Cury, Luiz Antônio Cunha e Roseli Fischmann, com quase duas centenas de presentes; e (b) o Encontro Aberto Fundamentalismos e Ciência: o papel do Estado e da Universidade, que extrapolou as presenças previstas, que seria de no máximo 20 pessoas, para cerca de 120 , tal o interesse despertado pelo tema. Ver, a respeito, Romano (2007).

5. Considerada como grande e emblemática vitória do grupo, o Ministério Público Federal de São Paulo, atendendo ao pedido da campanha "Brasil para Todos", iniciou ação civil pública pela retirada de crucifixos e símbolos religiosos dos espaços públicos.

6. Por exemplo, o abaixo- assinado mencionado por Cunha (2009, p. 278) é articulado pela campanha "Brasil para Todos" (disponível em: <www.petitiononline.com/BrasVat/ petition.html>).

7. Nesse sentido, vale notar a criação do Grupo de Estudos sobre Aborto (GEA), em agosto de 2007, coordenado pelo médico e pesquisador Thomaz Gollop, com apoio do Ministério da Saúde e de diversas instituições e pessoas, vindo a ser apoiado pela SBPC, em cuja sede se realiza a maior parte das reuniōes.

8. A imagem-trocadilho usando o prefixo se inspira em publicação da ONG CFEMEA (2009).

9. Por exemplo, cf. áudio da sessão da Comissão de Relaçôes Exteriores e Defesa Nacional, de 14 de julho de 2009.

10. Trata-se da autora deste artigo, Roseli Fischmann, que os deputados consideraram como pessoa que trataria o tema a partir da perspectiva acadêmica e não de uma ou outra religião. Buscavam, assim, a análise de um cientista social para evitar impasses entre diferentes grupos, fossem religiosos, fossem partidários da laicidade. Apenas um deputado manifestou-se contrário, ressaltando que seu desacordo não era em relação ao nome, mas em relação à realização de audiência para a matéria. Utilizo agora a primeira pessoa do singular: quando das sessões de audiência pública, em 7 e 14 de julho, destaquei que minha presença isolada, embora honroso o convite, era insuficiente para refletir o ser coletivo que sou como pesquisadora e, quanto à sociedade civil que precisaria ser ouvida, não dispunha de legitimidade para representar qualquer grupo, e que por isso deveriam ouvir outros representantes e outros acadêmicos. Nesse sentido, aproveito este artigo para agradecer aos colegas da área da Educação, de diferentes instituições brasileiras, das quais o CEDES é um exemplo, que vêm construindo, há décadas, uma tradição de debate sobre o ensino religioso nas escolas públicas, que tem sido meu "lar acadêmico", bem como às diferentes 
comunidades de minorias religiosas e de ateus, com quem tenho partilhado reflexões e aprendido sobre suas vivências. Agradeço, em especial, às companheiras do movimento feminista e de mulheres que, desde o início dos anos de 1990, têm me ensinado tanto, e em particular ao movimento de mulheres negras.

\section{Referências}

AGÊNCIA CÂMARA. Estatuto da Igreja Católica divide opiniões em audiência pública. Disponível em: <www.direitoshumanos.etc.br/ index.php?option=com_content $\&$ view=article $\&$ id $=2807$ : estatuto-daigreja-catolica-divide-opinioes-em-audiencia-publica- $\&$ catid $=19$ : civil\&Itemid=161>. Acesso em: 8 jul. 2009a.

AGÊNCIA CÂMARA. Comissão pode votar Estatuto da Igreja Católica. Disponível em: <http://www.camara.gov.br/internet/agencia/ imprimir.asp?pk=137596>. Acesso em: 15 jul. 2009 b.

ARANHA, A.; MENDONÇA, M. Jesus vai à escola. Época, São Paulo, p. 108-114, $1^{\circ}$ set. 2008. (Com Luciana Vicária e Thaís Ferreira). Parcialmente disponível em: <http://revistaepoca.globo.com/Revista/Epoca/ 0,,EMI1 1556-15204,00-JESUS+VAI+A+ESCOLA.html> (íntegra para assinantes). Acesso em: 15 jun. 2009.

ASSOCIAÇÃO DA PARADA DO ORGULHO GLBT DE SÃO PAULO. Histórico. Disponível em: <www.paradasp.org.br/historico.htm>. Acesso em: 10 jun. 2009.

ASSOCIAÇÃO BRASILEIRA DE ATEUS E AGNÓSTICOS (ATEA). Estatuto. Disponível em: <http://atea.org.br/index.php?option=com content\&view=article\&id=50\&Itemid=72>. Acesso em: 12 jun. 2009.

BRASIL. Câmara dos Deputados - DETAQ. Notas taquigráficas da sessão 182.3.53.0. Oradores: André Zacharow e Pastor Pedro Ribeiro. Brasília, DF, 14 jul. 2009.

BRASIL. Constituição dos Estados Unidos do Brasil, de 24 de fevereiro de 1891. Disponível em: <http://www.planalto.gov.br/ccivil_03/ Constituicao/Constitui\%C3\%A7ao91.htm>.

BRASIL. Decreto n. 1, de 15 de novembro de 1889. Disponível em: <http://www.cultura.al.gov.br/equipamentos-culturais/memorial-arepublica/decreto-n-1-de-15-de-novembro-de-1889>. 
A proposta de concordata com a Santa Sé e o debate na Câmara Federal

BRASIL. Decreto n. 119-a, de 7 de janeiro de 1890. Disponível em: <http://www.planalto.gov.br/ccivil_03/decreto/1851-1899/d119a.htm $>$.

BRASIL. Constituição da República Federativa do Brasil de 1988. Disponível em: <http://www.planalto.gov.br/ccivil_03/constituicao/ constitui\%C3\%A7ao.htm>

BRASIL. Acordo entre a República Federativa do Brasil e a Santa Sé sobre assistência religiosa às Forças Armadas, de 23 de outubro de 1989. Disponível em: <http://www2.mre.gov.br/dai/b_santa_03_3677.htm>

BRASIL. Mensagem n. 134, de 12 de março de 2009. Submete à apreciação do Congresso Nacional o texto do Acordo entre a República Federativa do Brasil e a Santa Sé, relativo ao Estatuto Jurídico da Igreja Católica no Brasil, assinado na Cidade-Estado do Vaticano, em 13 de novembro de 2008. Disponível em: <http://www.camara.gov.br/sileg/ integras/637903.pdf>.

CARNEIRO, S. Perigo. Correio Braziliense, Brasília, DF, 22 dez. 2006. Disponível em: <http://www.geledes.org.br/index.php?option=com content \&view=article \&id = 168:perigo \&catid $=130:$ sueli-carneiro \& Itemid=61>. Acesso em: 13 jun. 2009.

CENTRO FEMINISTA DE ESTUDOS E ASSESSORIA (CFEMEA). $O$ (des)acordo republicano. Brasília, DF: CFEMEA, 2009.

COMISSÃO DE CIDADANIA E REPRODUÇÃO. Avanço, retrocesso ou mais do mesmo. Ciência e Religião na Midia, 4 abr. 2007. Disponível em: <http://www.ccr.org.br/a_noticias_detalhes.asp?cod_ noticias=23>. Acesso em: 13 jun. 2009.

CORNWELL, J. O Papa de Hitler. Rio de Janeiro: Imago, 2002.

CUNHA, L.A. A educação na concordata Brasil-Vaticano. Educação \& Sociedade, Campinas, v. 30, n. 106, p. 263-280, jan./abr. 2009.

FISCHMANN, R. Ameaça ao Estado laico. Folha de S. Paulo, São Paulo, 14 nov. 2006. Cotidiano. Disponível em: <www1.folha.uol.com.br/fsp/ cotidian/ff1411200622.htm>. Acesso em: 13 jun. 2009.

FISCHMANN, R. Lula e o Estado laico. Folha de S. Paulo, São Paulo, 11 maio 2007. p. A-3. 
FISCHMANN, R. Cidadania e o projeto de lei "Deus na Escola”. Jornal da Ciência, v. 3375, p. 1-2, 2007.

JORNAL da Ciência. JC E-mail 3305, 13 jul. 2007. Disponível em: <http://www.jornaldaciencia.org.br/Detalhe.jsp?id=48701>. Acesso em: 13 jun. 2009.

LOREA, R.A. (Org.). Em defesa das liberdades laicas. Porto Alegre: Livraria do Advogado, 2008.

OLIVEIRA, F. Em nome da laicidade do Estado. Portal Mhario Lincoln do Brasil, 26/11/2009. Disponível em: <www.mhariolincoln.jor.br/antigo/index.php? catid=63\&blogid=1>. Acesso em: 13 jun. 2009.

PINHEIRO, M.C.B. Parada Gay (GLBT) 2008: o combate à homofobia e a separação Estado-Igreja. Jus Navigandi, Teresina, v. 12, n. 1789, 25 maio 2008. Disponível em: <http://jus2.uol.com.br/doutrina/texto. asp?id=11305>. Acesso em: 10 jun. 2009.

REZEK, F. Direito internacional público: curso elementar. 11. ed., rev. e atual. São Paulo: Saraiva, 2008.

ROMANO, R. Informe sobre o Estado laico na 59a Reunião Anual da SBPC. Belém, 8-13 jul. 2007. Disponível em: <http://robertounicamp. blogspot.com/2007/07/recebo-da-dra-roseli-fischmann-o-texto.html>. Acesso em: 13 jun. 2009. 